Nuntius Antiquus, Belo Horizonte, v. 13, n. 2, p. 153-171, 2017

\title{
$O$ dilema das relações internacionais sob a ascensão de Roma no Mediterrâneo, 350-200 a.C.
}

\section{The Dilemma of International Relations During the Rise of Roman Hegemony in the Mediterranean, 350-200 BC}

\author{
Rafael Scopacasa \\ Departamento de História \\ Universidade Federal de Minas Gerais, Belo Horizonte, Minas Gerais / Brasil \\ rafaelsco@hotmail.com
}

Resumo: A expansão da hegemonia romana no Mediterrâneo nos oferece um interessante estudo de caso para explorar a transição de uma anarquia para uma hierarquia internacional. Até que ponto, e de que maneira, a ascensão hegemônica romana (séculos IV-III a.C.) alterou a conduta dos Estados italianos, os primeiros a sentir os efeitos da supremacia romana? De que modo esses Estados reagiram às profundas mudanças no sistema internacional provocadas pela ascensão de Roma? Para abordar essas questões, é necessário seguirmos os relatos historiográficos de Políbio (200-120 a.C.) e Tito Lívio (59 a.C. - AD 17), cujas narrativas sobre a expansão romana inicial são as únicas que nos chegaram relativamente completas. Será proposto que, apesar de encontrarem-se subordinados à nova supremacia romana no século III a.C., muitos Estados italianos continuaram agindo como se fossem unidades autônomas e independentes no plano internacional.

Palavras-chave: Roma; teoria das Relações Internacionais; hegemonia; anarquia; historiografia antiga.

Abstract: The rise of Roman hegemony provides an interesting case-study on the transition from international anarchy to hierarchy. Italian polities were the first to experience the effects of Roman hegemonic power in the late fourth and third centuries BC. This paper investigates to what extent the rise of Roman hegemony altered the behaviour of Italian states on the international level, and how these states reacted to the profound changes in the international system brought about by Rome's unprecedented rise. To address these questions, I discuss the ancient historiographical accounts of 
Polybius (200-120 BC) and Livy (59 BC - AD 17), which constitute the most complete extant accounts of Rome's early expansion. I argue that although Italian states were subject to Roman supremacy by the early third century BC, they continued to behave as if they were independent and autonomous units in the international arena.

Keywords: Rome; International Relations theory; hegemony; anarchy; ancient historical writing.

\section{Introdução}

Desde o final da Segunda Guerra, a palavra império possui uma carga profundamente negativa - o que é compreensível, dadas as atrocidades que potências colonialistas cometeram em nome do avanço da civilização. Dissecamos o imperialismo e com razão o condenamos, auxiliados pelo sofisticado aparato teórico do pós-colonialismo. Entretanto, ao mesmo tempo, estamos profundamente acostumados com a existência de superpotências mundiais: nos últimos 70 anos os EUA, e anteriormente o império britânico. Em outras palavras: nascemos, crescemos e vivemos em um mundo criado e modelado pela dita hegemonia do Ocidente. Há sinais de que essa ordem mundial pode estar em processo de desagregação: segundo o documento Global Trends 2025: A Transformed World, produzido pelo National Intelligence Council dos EUA em 2008, a supremacia do Ocidente está com os dias contados, e o mundo caminha para uma ordem internacional multipolar. ${ }^{1}$ De acordo com as previsões feitas no documento, os EUA continuarão sendo a nação mais poderosa nas próximas décadas, mas sua ascendência diminuirá em prol de novas potências emergentes, sobretudo China e Rússia. ${ }^{2}$

Em outras palavras, começamos a vislumbrar alternativas à hegemonia global do West. Entretanto, para muitos especialistas, tais alternativas não são necessariamente reconfortantes. Segundo Kenneth Waltz, cientista político das Relações Internacionais, um mundo desprovido de potência hegemônica seria muito mais inseguro, violento e

\footnotetext{
${ }^{1}$ Disponível em: < https://www.dni.gov/files/documents/Newsroom/Reports\%20 and\%20Pubs/2025_Global_Trends_Final_Report.pdf> Acesso em: 22 out. 2017.

${ }^{2}$ Morris (2010).
} 
injusto. ${ }^{3} \mathrm{Na}$ ausência de um Estado com ascendência política, econômica e militar sobre os outros, não haveria, em última análise, nenhuma autoridade capaz de controlar os impulsos, as ambições e os excessos dos numerosos Estados, os quais se encontrariam livres para competir brutalmente entre si, sem nada ou ninguém para impedi-los. Nas palavras de Waltz, se instauraria uma anarquia internacional generalizada, uma "guerra de todos contra todos", na qual segurança, estabilidade e justiça se tornariam recursos extremamente escassos e preciosos. ${ }^{4}$

É necessário, de antemão, contextualizar o pensamento de Waltz no âmbito das teorias sobre o imperialismo. As teses clássicas sobre o imperialismo foram formuladas no início do século XX por Hobson e Lenin, e foram posteriormente desenvolvidas por Galtung e Wallerstein na década de 1970. Em termos gerais, esses autores definem o imperialismo como consequência natural e inevitável do capitalismo. ${ }^{5}$ Eles pressupõem que a política externa dos Estados é determinada, em última análise, por questões econômicas. Assim, eles definem o imperialismo como a exploração econômica dos países capitalistas ricos sobre os países pobres. Seguindo essa tese marxista-leninista, seriam os atributos socioeconômicos de cada Estado individual (capitalismo industrial desenvolvido, economia de exportação de bens primários, economia planificada) que determinariam se esse Estado é ou não imperialista: para ser imperialista, o Estado precisaria, logicamente, ser capitalista. Um óbvio obstáculo para esse raciocínio é caso da URSS e suas intervenções militares na China e no Afeganistão no pós-Segunda Guerra Mundial: temos aqui um Estado não capitalista comportando-se de maneira imperialista.

$\mathrm{Na}$ visão de Waltz, a principal falha da tese marxista-leninista - e suas muitas derivadas - é a premissa de que o imperialismo resulta dos atributos específicos de determinados Estados (por exemplo, a sua economia). O problema, como Waltz nos lembra, é que os Estados não existem no vácuo, mas estão inseridos em sistemas internacionais - isto é, um todo formado por unidades (Estados) que interagem de diversas formas

\footnotetext{
${ }^{3}$ Waltz (1979).

${ }^{4}$ Sobre anarquia internacional, guerra e segurança, cf. Waltz (1979, p. 104-16).

${ }^{5}$ Hobson (1902); Lenin (1916); Galtung (1971); Wallerstein (1974).
} 
e influenciam-se mutuamente. Logo, para entender o comportamento dos Estados no plano internacional - como o imperialismo -, é preciso considerar não somente os atributos específicos a cada Estado (isto é, se possuem uma economia capitalista desenvolvida ou não) mas também o próprio sistema internacional e a maneira como ele influencia no comportamento de Estados individuais. ${ }^{6}$

A teoria de Waltz sobre a anarquia internacional é bastante clara. Primeiro: em um sistema internacional anárquico, não existe uma autoridade suprema que possa controlar o uso da força entre os Estados que formam esse sistema. ${ }^{7}$ Consequentemente não há nenhuma garantia de que um Estado não vá agredir ou destruir outro a qualquer momento; logo, cada Estado precisa garantir a sua própria segurança, e a única maneira de fazê-lo efetivamente é impedindo que outros Estados o ataquem. Logo, em um sistema internacional anárquico, a segurança de um Estado é diretamente proporcional ao poder que esse Estado exerce sobre os outros. Visto que todos os Estados em uma anarquia buscarão maximizar seu poder sobre os outros, eventualmente um Estado consegue a hegemonia. Proposições questionáveis, mas que levantam um problema difícil de resolver: em um Estado de direito, a lei vale alguma coisa justamente porque pode ser aplicada forçosamente; sendo assim, o que ocorreria em um país onde não existisse uma força vigorosa $o$ suficiente para aplicar a lei ${ }^{8}$ Coloca-se um dilema: ao tentar escapar do imperialismo, acabaríamos por retornar a ele, por necessidade? Valeria

\footnotetext{
${ }^{6}$ Waltz discorda fundamentalmente de Lenin e Galtung (WALTZ, 1979, p. 31-4), ao manter que a política externa dos Estados não é determinada pelos atributos econômicos desses Estados. De acordo com Waltz, a noção de que, em países capitalistas, o Estado encontra-se totalmente subordinado aos interesses do grande capital é falha. Ele argumenta que empresas multinacionais, por mais poderosas que sejam, não conseguem controlar o Estado: ao contrário, é o Estado que ora permite, ora inibe o poder das multinacionais. Estados soberanos têm, por definição, a capacidade de decidir como lidar com problemas/limitações/imposições de outros (inclusive decisões sobre buscar ou não ajudas de parceiros mais fortes, e assim abrir mão de sua própria independência). ${ }^{7}$ Onde o autor denomina de "autoajuda" a condição de um Estado que precisa garantir sua própria segurança em um sistema internacional anárquico, cf. Waltz (1979, p. 116). ${ }^{8}$ Sobre comparação entre o âmbito do Estado-nação de direito e o sistema internacional, cf. Waltz (1979, p. 103-4).
} 
mais a pena viver sob a supremacia de uma potência e seus (eventuais) excessos, do que sob a constante ameaça de violência e aniquilação por parte de vizinhos que não conhecem limites? É possível escapar ao dualismo da questão formulada acima?

O mundo romano permite refletir sobre essas questões através de uma perspectiva histórica. ${ }^{9}$ A velocidade com que a república romana subiu à posição de líder hegemônica no Mediterrâneo já chamava atenção dos antigos, como é evidente na obra de Políbio, historiador grego que escreveu em meados do século II a.C.:

O aspecto do meu trabalho que é o melhor em si mesmo, e o mais instrutivo para os estudantes, é aquele que lhes permite compreender de que maneira, e com que tipo de constituição, ocorreu que quase o mundo inteiro caiu sob o poder de Roma, em pouco menos de 53 anos, um evento certamente sem precedentes. (POLÍBIO, 6.1) ${ }^{10}$

O sistema internacional do Mediterrâneo antigo mudou consideravelmente no século e meio antes de Políbio (300-150 a.C.), devido à ascensão hegemônica da república romana. Por "sistema internacional", entendo aqui um grupo de comunidades políticas ou Estados que interagem continuamente, seja cooperando ou competindo por poder e recursos. ${ }^{11}$ No linguajar da teoria das Relações Internacionais (RI), antes da ascensão de Roma, o Mediterrâneo teria constituído um sistema internacional multipolar, composto por numerosos estados poderosos de influência regional, como Tarento, Siracusa, Cápua e as principais cidades etruscas, Cartago, e os poderosos reinos helenísticos (Egito, Império Selêucida e Macedônia). ${ }^{12}$

Na Itália, a situação geopolítica já começara a mudar consideravelmente desde o momento em que Roma expulsou o rei Pirro em 275 a.C.: àquela altura, Roma já havia derrotado seus principais rivais

\footnotetext{
${ }^{9}$ Eckstein (2006) fez um estudo pioneiro nesse sentido; ver também Fronda (2010).

${ }^{10}$ Todas as citações de autores antigos são traduções feitas pelo autor, com base nas edições em inglês.

${ }^{11}$ Sobre o conceito de sistema internacional, cf. Evans; Newnham (1998, p. 550).

${ }^{12}$ Eckstein (2006, p. 118-20).
} 
na península, sobretudo as grandes cidades-Estados etruscas de Caere, Tarquinii e Vulci, a poderosa federação samnita e a formidável polis de Taranto, no extremo sul. Além disso, Roma já tinha começado a fundar colônias e a construir uma extensa rede de estradas que atravessaram a península e criavam uma nova geografia centrada em Roma. ${ }^{13}$ No linguajar das RI, Roma estava gradualmente transformando o sistema internacional da Itália (e, posteriormente, do Mediterrâneo), de uma anarquia para uma hierarquia internacional.

Por esse motivo, a expansão romana nos oferece um interessante estudo de caso para explorar em que medida a transformação no sistema internacional afetou os Estados envolvidos nesse processo, que deixaram de ser unidades autônomas e passaram a ser subordinados a uma potência hegemônica. Até que ponto a ascensão hegemônica romana entre os séculos IV e III a.C. alterou a conduta dos Estados italianos, os primeiros a sentir os efeitos do poder hegemônico romano? De que modo esses Estados reagiram às profundas mudanças no sistema internacional provocadas pela ascensão de Roma?

Segundo a escola Realista das Relações Internacionais, a instauração de uma hierarquia internacional, teoricamente, provoca mudanças consideráveis no comportamento dos Estados envolvidos: tais Estados não mais precisam garantir a sua própria segurança e assim passam a contar com a superpotência para sua própria proteção. ${ }^{14}$ Consequentemente, as guerras endêmicas, características da anarquia, cedem lugar à interdependência e cooperação entre os Estados. Em que medida a transformação de Roma em autoridade suprema, capaz de controlar o uso da violência entre os Estados italianos, fez com que esses Estados ficassem menos agressivos e mais dispostos a cooperar mutuamente?

Para abordar essa questão, é necessário considerar os relatos historiográficos de Políbio (200-120 a.C.) e Tito Lívio (59 a.C. - AD 17), cujas narrativas sobre a expansão romana inicial são as únicas

\footnotetext{
${ }^{13}$ Sobre colonização romana durante o período republicano, cf. Bradley; Wilson (2006); Pelgrom; Stek (2015). Sobre estradas, cf. Laurence (1999).

${ }^{14}$ Lake (2009, p. 10-12); Schweller (1994).
} 
que nos chegaram relativamente completas. ${ }^{15}$ Apesar de serem textos romanocêntricos e tardios em relação ao período narrado, eles nos fornecem dados importantes sobre as ações e o comportamento dos Estados italianos (e mediterrânicos) em relação a Roma; a partir desses dados, podemos formular algumas hipóteses sobre as motivações e percepções que podem ter guiado a conduta desses Estados, e elaborar uma breve reflexão sobre como essa conduta mudou com a ascensão de Roma.

\section{De anarquia a hierarquia: a ascensão romana e seu impacto no sistema internacional}

O historiador romano Tito Lívio, no início do seu sétimo livro, afirma que a segunda metade do século IV a.C. foi o momento em que Roma começou a enfrentar seriamente as ameaças que a cercavam:

Guerras de maior magnitude, em relação tanto às forças de nossos inimigos quanto à distância de seus países e os longos períodos de tempo envolvidos, agora serão relatadas. Pois naquele ano [343 a.C.] a espada foi erguida contra os Samnitas, um povo poderoso em armas e em recursos; e logo depois da guerra Samnita, travada com vários sucessos, veio a guerra com Pirro, e depois dessa com os cartagineses. Quão vasta essa série de eventos! Quantas vezes incorreuse em extremo perigo, para que nosso império pudesse ser exaltado à sua grandeza presente, dificilmente mantida! (LÍVIO, 7.19)

Lívio se refere àquilo que ele identifica como o início de uma nova fase no processo de expansão romana - o momento em que os romanos teriam começado, de fato, a lidar com adversários importantes no cenário internacional. A primeira dessas ameaças foram os Samnitas, uma federação de povos itálicos que controlava boa parte do centrosul da península. Lívio afirma que, em 354 a.C., Samnitas e Romanos

\footnotetext{
${ }^{15}$ Sobre um comentário extensor e minucioso sobre Lívio, sua obra e suas fontes; e sobre a importante discussão das dificuldades interpretativas que o texto de Lívio nos apresenta, cf. Oakley (1997-2005).
} 
concluíram um acordo de aliança e amizade (societate amicitiaque). ${ }^{16}$ Esse tipo de acordo provavelmente buscava criar alguma forma de segurança internacional em um ambiente anárquico, desprovido de lei internacional. ${ }^{17}$ Mas, embora a amicitia entre Roma e os Samnitas tivesse essa função pretendida, o fato de que ela desabou apenas onze anos depois revela a fragilidade intrínseca de tais acordos. De acordo com Lívio, em 343 a.C., os Samnitas atacaram um povo vizinho, os Sidicinos; esses, por sua vez, pediram ajuda à cidade de Cápua, na rica e fértil região da Campânia. Em resposta, os Samnitas começaram a planejar um ataque a Cápua. Os Capuanos, temerosos, pediram ajuda a Roma, provavelmente por meio de uma deditio - isto é, uma rendição formal da cidade em troca de proteção. Roma aceitou a rendição dos capuanos e advertiu os samnitas (que ainda eram seus aliados) a desistir de invadir; os samnitas rejeitaram o aviso, e a guerra começou. ${ }^{18}$

Há muita ambiguidade no relato de Lívio sobre esses acontecimentos. Por um lado, Roma pode ter usado a crise como um pretexto para se apoderar da riqueza de Cápua e de suas terras férteis. Alternativamente, ao aceitar a rendição de Cápua, Roma poderia ter procurado mitigar a situação, declarando abertamente que os samnitas precisariam lidar com as forças romanas se insistissem em invadir Cápua. ${ }^{19}$ Ao fim, Roma conseguiu proteger Cápua, e a guerra terminou em 341. Mas apenas alguns meses depois, Cápua voltou-se contra Roma, na Guerra Latina de 341-338 a.C. A nova situação era o oposto da de 343: aqui, os Samnitas apoiaram Roma, que estava contra Cápua. ${ }^{20}$ Esta aliança romano-samnita durou até 327/6 a.C., quando novamente colapsou por causa de outra crise na Campania, desta vez envolvendo Nápoles. ${ }^{21} \mathrm{Na}$ versão de Lívio, Nápoles atacou aliados romanos na Campânia; Roma pediu que as agressões cessassem, mas Nápoles ignorou o pedido, levando

\footnotetext{
${ }^{16}$ Lívio (7.19.4).

${ }^{17}$ Burton (2011, p. 86-90, 123-25).

${ }^{18}$ Sobre uma narrativa dos acontecimentos que levaram à guerra, cf. Lívio (7.29-31). Lívio é a única fonte que menciona esse primeiro conflito entre Roma e os Samnitas.

${ }^{19}$ Burton (2011, p. 123-25).

${ }^{20}$ Lívio (8.2-6).

${ }^{21}$ Cf. Lívio (8.22.7-10) e Dionísio de Halicarnasso, Ant.Rom (15.5-8).
} 
Roma a declarar guerra. A esta altura, os Samnitas (que ainda eram aliados romanos) teriam intervido em favor de Nápoles, com a assistência de Taranto. É possível que a intervenção samnita em favor de Nápoles (com o apoio dos Tarentinos) tivesse por objetivo impedir uma guerra em larga escala na Campânia, dissuadindo os romanos de atacar. Por outro lado, os Samnitas poderiam estar procurando uma desculpa para ir à guerra; eles podem ter visto a crescente tensão entre Roma e Nápoles como uma oportunidade para invadir a região e se apoderar das suas riquezas.

Quaisquer que tenham sido as motivações específicas dos Estados envolvidos, as crises de 343, 341 e 327/6 a.C. parecem indicar o seguinte: como não existia nenhuma autoridade superior, poderosa o suficiente para fazer cumprir acordos internacionais (amicitia, alianças ou outros), a eficácia desses acordos teria sido muito limitada. Nem Roma, nem Cápua, nem os Samnitas podiam partir do pressuposto de que acordos de não agressão recíproca seriam respeitados - ao contrário, todos esses Estados precisavam agir por conta própria para garantir a sua segurança. A ausência de um poder hegemônico capaz de fazer cumprir o direito internacional - e mesmo a inexistência de tal direito internacional teria incentivado os Estados a perseguirem os seus próprios interesses através de estratégias de autoajuda, de acordo com as contingências. Os resultados de tais medidas de autoajuda tendiam a ser de curto prazo: daí a aparente facilidade com que os jogadores no cenário internacional - Roma, a federação samnita, Cápua - mudam de lado. No intervalo de apenas 13 anos, de 354 a 341 a.C., a relação entre Roma e os Samnitas fez um círculo completo, e continuou a mudar nas décadas seguintes. Cápua, por outro lado, implorou a proteção romana em 343, mas apenas dois anos depois tomou o lado das cidades latinas contra Roma.

É possível fazer uma segunda inferência com base nos episódios acima: Estados cujas constituições políticas parecem ter sido semelhantes estavam, entretanto, presos em ciclos de violência endêmica. Tanto Roma quanto Cápua eram cidades-Estados autônomas, e ambas tinham sistemas republicanos de governo - embora estejamos muito mais bem informados sobre o republicanismo romano em particular. ${ }^{22}$ Em ambos os Estados,

\footnotetext{
${ }^{22}$ Sobre Roma, cf. Scopacasa (no prelo). Sobre Cápua, cf. Scopacasa $(2015,2016)$.
} 
o governo era coletivo, com assembleias de cidadãos que deliberavam sobre questões de política interna e externa, inclusive a guerra. Entretanto, a aparente compatibilidade entre Roma e Cápua em termos de cultura política não parece ter sido capaz de gerar condições para que esses Estados conseguissem resolver suas diferenças com base na diplomacia ou na mediação: tamanha era a pressão que o sistema internacional anárquico parece ter exercido sobre esses Estados, impelindo-os a manter uma postura recorrentemente agressiva um com o outro - já que, talvez, essa postura teria sido a única forma realmente eficaz de um Estado garantir a sua própria segurança naquelas condições.

Esse ambiente internacional anárquico da segunda metade do século IV a.C. transformou-se profundamente, na medida em que a república Romana afirmou sua supremacia, primeiro na Itália e depois no Mediterrâneo. ${ }^{23}$ As primeiras grandes mudanças vieram, talvez, em 338 a.C., quando Roma começou a articular a sua poderosa rede de aliados e colônias, depois de derrotar a Liga Latina. ${ }^{24}$ Em 295, os romanos conseguiram derrotar um enorme exército conjunto de Samnitas, Etruscos, Úmbros e Gauleses, perto da cidade de Sentinum, na Úmbria, no que provavelmente foi o maior confronto militar na Itália peninsular até aquele momento. ${ }^{25}$ Vinte anos depois, em 275, Roma expulsava da Itália Pirro, rei de Épiro, que havia ido à península com o objetivo de conquistá-la cinco anos antes, com o apoio de Taranto. Apenas três anos após a expulsão de Pirro, foi a vez dos Tarentinos: Roma demoliu as muralhas da cidade e instaurou uma guarnição em seu interior. ${ }^{26} \mathrm{~A}$ antiga hegemonia dos Tarentinos sobre o Sul da Itália chegava ao fim.

No linguajar da teoria realista, pode-se afirmar que o sistema internacional italiano em 272 a.C. já estava bem menos anárquico - e consideravelmente mais hierárquico - do que em 343, quando o primeiro conflito entre Roma e os Samnitas começou (ver acima). Em 272, Roma

\footnotetext{
${ }^{23}$ Cf. Eckstein (2006, p. 253; 2008, p. 20); Fronda (2010, p. 21-23); Serrati (2006, p. 127); Scopacasa (2016).

${ }^{24}$ Lívio (8.13-14).

${ }^{25}$ Lívio (10.27).

${ }^{26}$ Eckstein (2006, p. 153).
} 
já havia derrotado todos os seus principais Estados rivais na Itália - bem como um monarca helenístico de além-mar. ${ }^{27}$ Ao mesmo tempo, colônias romanas e confiscos de terra espalhavam-se pela península. ${ }^{28} \mathrm{~A}$ fundação de colônias romanas foi acompanhada pela construção de estradas romanas como a Via Flamínia (220 a.C.), que ligava Roma à colônia de Ariminum no litoral Adriático. Tais estradas parecem ter alterado significativamente a geografia da Itália, criando novas redes e vias de comunicação cujo centro era Roma. Elas eram também um importante símbolo da nova ascensão romana. ${ }^{29}$

Portanto, não é surpreendente que Roma tenha começado a reivindicar um domínio sobre a Itália justamente nesse período de grandes mudanças geopolíticas. Sugeriu-se que tais ambições hegemônicas romanas despontaram já no fim do século IV a.C., em vista de um suposto tratado romano-cartaginês conhecido como o "Tratado de Philinus". ${ }^{30}$ Esse documento supostamente proibia os cartagineses de interferir militarmente na Itália, dando a entender que os romanos estavam reivindicando a península toda como a sua área de influência exclusiva. ${ }^{31}$ Nesse respeito, o tratado de Philinus diferiria do anterior tratado romanocartaginês, de 348 a.C., no qual aparentemente permitia-se que Cartago saqueasse cidades italianas. ${ }^{32}$ Políbio é a nossa única fonte que menciona o tratado de Philinus, mas há sérias dúvidas sobre a veracidade histórica desse documento. O próprio Políbio negava a existência desse tratado, e recentemente o romanista Arthur Eckstein reforçou essa posição com argumentos convincentes. ${ }^{33}$ Sinais mais seguros de uma nascente ambição hegemônica romana podem ser encontrados em narrativas sobre a guerra entre Roma e Pirro, rei de Épiro (280-275 a.C.: ver acima). Políbio

${ }^{27}$ Sobre a vitória romana sobre Pirro ter projetado a cidade como nova potência em nível mediterrânico, cf. Crawford (1992, p. 45-6); Forsythe (2005, p. 358); Fronda (2010, p. 23).

${ }^{28}$ Cf. Bradley; Wilson, 2006; Pelgrom; Stek (2015); Scopacasa (2016).

${ }^{29}$ Laurence (1999).

${ }^{30}$ Serrati (2006). (Com bibliografia).

${ }^{31}$ Políbio (3.26).

${ }^{32}$ Políbio (3.24).

${ }^{33}$ Cf. Políbio (3.26.2-4); Eckstein (2010). 
afirma claramente que foi esse o momento em que os romanos passaram a atacar o resto da Itália, não como se fosse um país estrangeiro, mas como se ela por direito lhes pertencesse. ${ }^{34}$ Tal afirmação é reforçada por um outro dado importante presente na tradição historiográfica romana sobre a Guerra Pírrica: em 280 a.C., logo no início do conflito, Roma sofreu uma séria derrota na batalha de Heracléia, no Sul da Itália, e Pirro aproveitou de seu sucesso inicial para oferecer um acordo de paz. Entretanto, apesar de sua posição enfraquecida, os romanos recusaram a oferta de Pirro e exigiram que o rei saísse da Itália como pré-condição para qualquer negociação. ${ }^{35}$ Tal episódio, se transmitido corretamente pela tradição historiográfica, parece corroborar a visão de Políbio: já em 280 a.C., parecemos estar assistindo ao nascimento de uma nova percepção geopolítica romana da península italiana como uma entidade coesa sob a autoridade romana. O que é mais difícil de saber é até que ponto os Estados italianos reconheciam, aceitavam e/ou rejeitavam esse ponto de vista, ainda nessa fase inicial da hegemonia romana, e em que medida tal percepção afetou o comportamento desses Estados italianos, tanto para com Roma como entre si.

As fontes disponíveis para tal estudo apresentam dois grandes obstáculos: são fragmentárias e retrospectivas. Os livros de Lívio que narram os anos entre 293 e 218 a.C. estão perdidos: temos apenas resumos curtos, escritos na Antiguidade Tardia. Políbio, por outro lado, inicia seu relato pouco antes da Segunda Guerra Púnica (218-202 a.C.), e fornece um breve panorama das décadas anteriores ao conflito. E é em Políbio que encontramos uma avaliação mais nuançada de como os italianos percebiam seu próprio sistema internacional e a posição de Roma nesse sistema.

Em 225 a.C., hordas gaulesas invadiram a Itália. Políbio afirma que a invasão alarmou os cônsules romanos, que imediatamente convocaram os aliados italianos a prestar auxílio - inclusive os Samnitas, que na ocasião formaram boa parte dos contingentes aliados que vieram à ajuda de Roma. As forças romanas e italianas confrontaram os gauleses em Telamon, uma localidade na Etrúria no litoral do Mar Tirreno, e

\footnotetext{
${ }^{34}$ Políbio (1.6.6).

${ }^{35}$ Cf. Apiano, Samnitika (10.2); Plutarco, Pirro (19.1-3).
} 
foram vitoriosas..$^{36} \mathrm{O}$ interessante, no entanto, é a observação de Políbio de que os Estados italianos responderam ao apelo romano, não porque julgassem necessário obedecer a comandos romanos, ou porque eles se viam como aliados romanos, mas sim porque esses Estados italianos estavam tão ansiosos quanto os romanos para deter os gauleses e expulsálos o mais rápido possível. Ao refletir sobre os motivos dos italianos, Políbio observa que eles não estavam preocupados se suas ações iriam acabar fortalecendo a hegemonia romana na Itália:

De todos os lados havia uma disposição pronta para ajudar de todas as maneiras possíveis; pois os habitantes da Itália, aterrorizados pela invasão dos gauleses, já não se consideravam aliados de Roma, nem consideravam esta guerra como empreendida para estabelecer a supremacia romana, mas cada homem considerou que o perigo estava descendo sobre si mesmo e sua própria cidade e país. Então, houve grande alacridade em obedecer ordens [grifo meu]. (POLÍBIO, 2.23.11-13)

Políbio parece estar sugerindo que, ao ajudar os romanos a expulsar os gauleses, os italianos estavam de fato ajudando a eliminar uma ameaça fundamental à hegemonia romana. Parece que, na visão de Políbio, os aliados italianos não estavam cientes de que a expulsão dos gauleses reforçaria a hegemonia romana na Itália; alternativamente, eles não viam o fortalecimento da hegemonia romana como boa razão para não expulsar os gauleses. De qualquer forma, o testemunho de Políbio levanta a interessante possibilidade de que, embora Roma fosse indiscutivelmente o poder hegemônico em 225 a.C., os Estados italianos não necessariamente viam-na como algo que determinasse qual política externa eles deveriam seguir. Políbio provavelmente estava ciente de que Roma teria sido capaz de forçar os italianos a cumprir suas ordens. ${ }^{37}$ No entanto, em termos de como os próprios italianos “julgavam” (hegoúnto)

\footnotetext{
${ }^{36}$ Políbio (2.23-25).

${ }^{37}$ Sobre a supremacia romana como relativamente consolidada desde o início do século III, notando instâncias em que Roma parece ter interferido nos assuntos internos de Estados italianos, cf. Bispham (2007, p. 53-5).
} 
a situação, eles podem ter acreditado que expulsar os gauleses era necessário para sua própria segurança, e que os desejos de Roma sobre esta (e possivelmente outras) questões internacionais eram secundários.

Uma sugestão semelhante pode ser feita em vista dos tumultuosos desenvolvimentos da Segunda Guerra Púnica (218-202 a.C.). Tanto Lívio quanto Políbio se concentram no que foi provavelmente o evento mais importante nos primeiros anos da guerra, a saber: a derrota esmagadora de Roma e seus aliados na batalha de Cannae, em 216 a.C. A vitória cartaginesa em Cannae teve um impacto tremendo sobre o sistema internacional na Itália. Um grande número de Estados italianos abandonaram sua aliança com Roma e foram para o lado de Aníbal. ${ }^{38}$ Mesmo depois de décadas de estarem sujeitos a uma relação de poder assimétrica com Roma, os Estados italianos não deixaram de ser capazes de decidir sua própria política externa, agindo como estados independentes, negociando suas próprias alianças. ${ }^{39}$

Os casos mais bem documentados sugerem que a política externa dos Estados italianos após Cannae foi, em grande parte, guiada por afinidades e rivalidades entre eles mesmos, e não tanto por sua relação com Roma. Conforme demonstrou recentemente Michael Fronda, as cidades de Atella, Calatia e Sabata seguiram a poderosa vizinha Cápua, ao abandonarem a aliança com Roma e irem para o lado de Aníbal. ${ }^{40}$ Tais decisões fazem sentido quando vemos essas mesmas quatro cidades agiram juntas um século antes, no início da segunda grande guerra entre Roma e a federação dos Samnitas (326-304 a.C.), embora naquela ocasião elas estivessem aliadas a Roma. Por outro lado, as cidades de Nápoles e Nola, antigas rivais de Cápua, lutaram juntas contra Roma e do lado dos Samnitas em 326 a.C., e, juntas, elas permaneceram leais a Roma depois da derrota de Cannae em 216 a.C. ${ }^{41}$

Tais casos parecem sugerir que as decisões de política externa dos Estados italianos nem sempre eram guiadas pela preocupação se

\footnotetext{
${ }^{38}$ Lívio (22.61).

${ }^{39}$ Fronda (2010, p. 4).

${ }^{40}$ Fronda (2010, p. 126-45).

${ }^{41}$ Fronda (2010, p. 126-45).
} 
Roma deveria ou não continuar sendo uma potência hegemônica. Ao contrário, tais decisões parecem ter sido informadas por uma gama mais ampla de rivalidades e afinidades entre os próprios Estados italianos. Aqui, novamente, temos a impressão de que Roma, e a questão da liderança romana, eram de certa forma vistas como secundárias pelos Estados italianos - os quais, entretanto, encontravam-se sob a crescente autoridade dessa nova potência hegemônica.

\section{Conclusão}

Antes que Roma se tornasse a potência hegemônica incontestada, o Mediterrâneo estava mergulhado em um contexto de anarquia internacional - no sentido de que não existia uma autoridade superior que pudesse regular o uso da força bruta entre as diversas comunidades políticas que compunham aquele sistema internacional - as várias cidades-Estados, Estados territoriais, federações etc. Em outras palavras, não existia nenhuma garantia real de que um Estado não atacaria outro. Consequentemente, o sistema internacional teria pressionado esses Estados a serem agressivos uns com os outros - ou no mínimo a manterem uma atitude profundamente desconfiada uns dos outros.

Tal situação parece adequar-se, em linhas gerais, àquilo que a teoria realista prevê como norma em sistemas internacionais anárquicos: se qualquer Estado podia, a qualquer momento, recorrer à violência, todos esses Estados ou comunidades teriam que estar preparados para fazer uso da violência a qualquer momento - e, em casos mais extremos, para atacar preemptivamente. Diplomacia existia, mas a sua eficácia é questionável: mesmo quando acordos de não agressão mútua eram feitos, como aquele entre Roma e a liga Samnita em 354 a.C., não havia uma autoridade suficientemente poderosa para forçar adesão e respeito a esses acordos.

A ascensão de Roma teria representado o fim dessa realidade volátil, violenta e um tanto distópica? Sem querer chegar a uma resposta conclusiva para essa questão, o que podemos constatar, com base nessa breve reflexão, é que o mundo antigo pode nos ajudar a pensar sobre dilemas modernos a partir de pontos de vista diferentes. 
O que parece especialmente interessante é o comportamento dos Estados italianos, tal como sugerido pelo relato dos episódios de Telamon em 225 a.C., e de Cannae em 216 a.C. Mesmo depois de várias décadas de sujeição ao poder de Roma, esses Estados aparentemente não eram capazes de colocar suas antigas rivalidades de lado em favor de uma causa em comum, fosse ela apoiar ou combater Roma. Muito embora Roma já fosse hegemônica desde o início do século III a.C., os Estados italianos, que estariam, na prática, sujeitos a essa hegemonia, parecem não ter percebido a sua própria situação como uma de sujeição: Roma não era vista como mestre, mas como uma igual, com quem se podia formar e romper alianças conforme a situação exigisse, muito como as poleis gregas tradicionalmente relacionavam-se entre si.

Entretanto, Roma já estava longe de ser uma igual. Ela derrotou Aníbal em 202 a.C., e apenas quarenta anos depois estava consolidando seu poder sobre a Grécia e o Mediterrâneo Oriental, fazendo frente aos temerários reinos helenísticos de Antíoco, Filipe V e Perseu. ${ }^{42}$ Os Estados italianos que apoiaram os cartagineses após Cannae foram severamente punidos. Aparentemente, a geopolítica mudou mais rápido do que a maneira como os Estados italianos percebiam a geopolítica. De certa forma, os primeiros Estados sujeitos à hegemonia romana parecem ter desenvolvido uma percepção do crescimento hegemônico de Roma como algo meramente secundário. À primeira vista, esse descompasso entre realidade e percepção geopolítica pode ter sido útil para Roma: pode ter sido conveniente aos interesses romanos que os Estados italianos continuassem acreditando que eles eram essencialmente livres, quando na prática eles já não o eram inteiramente.

Os Estados italianos estavam tão habituados a atuar como jogadores autônomos em um sistema internacional anárquico, que, mesmo após décadas de subordinação a Roma, esse hábito ou disposição cultural ainda se encontrava firme e forte. Caso contrário, os italianos não teriam reagido da maneira que reagiram ao vácuo de poder causado pela derrota romana em Cannae - isto é, como unidades independentes sem uma causa em comum. A ascensão de Roma pode, a longo prazo, ter

\footnotetext{
${ }^{42}$ Eckstein (2006).
} 
eliminado a guerra endêmica que parece ter assolado a Itália e boa parte do Mediterrâneo durante séculos. Mas antes que isso pudesse acontecer, os velhos hábitos anárquicos precisavam morrer. Aparentemente, eles custaram para fazê-lo.

\section{Referências}

APPIAN. Roman History. Edited and translated by Brian McGing. Loeb Classical Library 2. Cambridge, MA: Harvard University Press, 1912. v. I. BISPHAM, E. From Asculum to Actium: the Municipalisation of Italy from the Social War to Augustus. Oxford: Oxford University Press, 2007.

BRADLEY, G. J.; WILSON, J. P. (Org.). Greek and Roman Colonisation: Origins, Ideologies and Interactions. Swansea: Classical Press of Wales, 2006.

BURTON, P. Friendship and Empire: Roman Diplomacy and Imperialism in the Middle Republic (353-146 BC). New York: Cambridge University Press, 2011.

CRAWFORD, M. The Roman Republic. Cambridge MA: Harvard University Press, 1992.

DIONYSIUS OF HALICARNASSUS. Roman Antiquities. Translated by Earnest Cary. Loeb Classical Library 388. Cambridge, MA: Harvard University Press, 1950. v. VII: Books 11-20.

ECKSTEIN, A. M. Mediterranean Anarchy, Interstate War, and the Rise of Rome. Berkeley: University of California Press, 2006.

ECKSTEIN, A. M. Polybius, the 'treaty of Philinus', and Roman accusations against Carthage. The Classical Quarterly, Cambridge, v. 60, n. 2 , p. 406-26, 2010.

ECKSTEIN, A. M. Rome enters the Greek East. From Anarchy to Hierarchy in the Eastern Mediterranean. Oxford: Blackwell, 2008.

EVANS, G.; NEWNHAM, J. (Org.). The Penguin Dictionary of International Relations. London: Penguin, 1998.

FORSYTHE, G. A Critical History of Early Rome: From Prehistory to the First Punic War. Berkeley: University of California Press, 2005. 
FRONDA, M. Livy 9.20 and early Roman imperialism in Apulia. Historia: Zeitschrift für Alte Geschichte, Erfurt, v. 55, n. 4, p. 397-417, 2006.

FRONDA, M. Between Rome and Carthage: Southern Italy during the Second Punic War. Cambridge: Cambridge University Press, 2010.

GALTUNG, J. A structural theory of imperialism. Journal of Peace Research, Oslo, v. 8, n. 2, p. 81-117, 1971.

HOBSON, J.A. Imperialism: a study. London: Allen and Unwin, 1948.

LAKE, D.A. Hierarchy in International Relations. Ithaca: Cornell University Press, 2009.

LAURENCE, R. The Roads of Roman Italy. London: Routledge, 1999.

LENIN, V.I. O imperialismo, fase superior do capitalismo. Lisboa: Avante, 1975.

LIVY. History of Rome. Translated by B. O. Foster. Loeb Classical Library 172. Cambridge, MA: Harvard University Press, 1924. v. III: Books 5-7.

LIVY. History of Rome. Translated by B. O. Foster. Loeb Classical Library 191. Cambridge, MA: Harvard University Press, 1926. v. IV: Books 8-10.

LIVY. History of Rome. Translated by B. O. Foster. Loeb Classical Library 233. Cambridge, MA: Harvard University Press, 1929. v. V: Books 21-22.

OAKLEY, S.P. A Commentary on Livy. Oxford: Oxford University Press, 1997-2005. Books VI-X.

PLUTARCH. Lives. Translated by Bernadotte Perrin. Loeb Classical Library 101. Cambridge, MA: Harvard University Press, 1920. v. IX: Demetrius and Antony. Pyrrhus and Gaius Marius.

POLYBUS. The Histories. Translated by W. R. Paton. Revised by F. W. Walbank, Christian Habicht. Loeb Classical Library 137. Cambridge, MA: Harvard University Press, 2010. v. I: Books 1-2.

POLYBUS. The Histories. Translated by W. R. Paton. Revised by F. W. Walbank, Christian Habicht. Loeb Classical Library 137. Cambridge, MA: Harvard University Press, 2010. v. II: Books 3-4. 
POLYBUS. The Histories. Translated by W. R. Paton. Revised by F. W. Walbank, Christian Habicht. Loeb Classical Library 138. Cambridge, MA: Harvard University Press, 2011. v. III: Books 5-8.

SCHWELLER, R. L. Bandwagoning for profit: bringing the revisionist state back in. International Security, Cambridge MA, v. 19, n. 1, p. 72102, 1994.

SCOPACASA, R. Ancient Samnium. Settlement, Culture and Identity between History and Archaeology. Oxford: Oxford University Press, 2015.

SCOPACASA, R. Rome's encroachment on Italy. In: COOLEY, A. (Org.). A Companion to Roman Italy. Oxford: Wiley-Blackwell, 2016. p. 35-56.

SERRATI, J. Neptune's altars. The treaties between Rome and Carthage (509-226 BC). The Classical Quarterly, Cambridge, v. 56, n. 1, p. 113134, 2006.

PELGROM, J.; STEK, T. (Org.). Roman Republican Colonization: New Perspectives from Archaeology and History. Roma: Palombi Editore, 2014.

WALLERSTEIN, I. The rise and future demise of the world capitalist system: concepts for comparative analysis. Comparative Studies in Society and History, Cambridge, v. 16, n. 4, p. 387-415, 1974.

WALTZ, K. Theory of International Politics. New York: McGraw-Hill, 1979.

Recebido em 26 de setembro de 2017. Aprovado em 22 de outubro de 2017. 